\title{
Inmunogenicidad de la enzima similar a trombina del veneno de la serpiente peruana Bothrops atrox y su evaluación por métodos inmunoenzimáticos.
}

\author{
Immunogenicity of Thrombin-like enzyme from Bothrops atrox Peruvian snake venom and its \\ evaluation by immunoenzimatic methods
}

Gustavo A. Sandoval ${ }^{1}$, Yrma Espinoza ${ }^{2}$, Dan Vivas ${ }^{1}$, Edith Rodriguez $^{1}$, Fanny Lazo $^{1}$ y Armando Yarlequé ${ }^{1}$

\section{RESUMEN}

Objetivo: Realizar una evaluación inmunogénica de la EST del veneno de $B$. atrox y determinar su grado de reactividad contra los venenos de las principales serpientes venenosas del país. Materiales y métodos: Se inmunizaron conejos albinos $(2.5 \mathrm{Kg})$ con $150 \mu \mathrm{g}$ de la enzima purificada basándose en protocolos estandarizados en nuestro laboratorio. Una vez obtenido el suero hiperinmune anti-EST, se analizaron los patrones de reactividad entre el suero experimental y la enzima purificada, así como contra los venenos totales de Bothrops atrox, Bothrops brazili, Lachesis muta y Crotalus durissus, empleando la técnica de ELISA. Resultados: Se obtuvo, al final del protocolo de inmunización, un suero anti-EST con un título de 64000. Por otro lado, los anticuerpos producidos reaccionaron de forma cruzada con los venenos completos de $B$. atrox $(9.9 \%)$ y B. brazili $(9.6 \%)$, y menor intensidad con los de L. muta (5.1\%) y C. durissus $(4.8 \%)$. Conclusión: La enzima similar a trombina (EST) de B. atrox presenta un elevado potencial inmunogénico, así como una baja reactividad cruzada con otros venenos de serpientes peruanas, por lo que resultaría en una proteína candidato para la elaboración de un kit de diagnóstico rápido y específico del envenenamiento ofídico por esta serpiente.

PALABRA CLAVE: antiveneno, inmunogenicidad, ELISA, veneno, serpiente.

\begin{abstract}
Objective: Perform an immunological evaluation of the TLE from B. atrox venom and to determine the grade of reactivity against venoms from other Peruvian snakes. Materiales and methods: As part of the experimental procedure, white rabbits $(2.5 \mathrm{Kg})$ were immunized using $150 \mu \mathrm{g}$ of the $B$. atrox TLE purified based on protocols standardized in our laboratory. After obtaining hiperimmune serum anti-TLE, reactivity patterns between this serum and purified TLE, as well as complete venoms of Bothrops atrox, Bothrops brazili, Lachesis muta and Crotalus durissus, were evaluated following ELISA technique. Results: At the end of immunization protocol, we obtained an anti-TLE serum with a title of 64000 . On the other hand, obtained polyclonal antibodies cross-reacted with the venoms of B. atrox (9.9\%), B. brazili (9.6\%), L. muta $(5.1 \%)$ and $C$. durissus $(4.8 \%)$. Conclusion: That TLE from B. atrox venom shows a high immunogenic potential, as well as a low cross-reactivity with other Peruvian snake venoms, and would be considered as a candidate protein to elaborate a fast and specific diagnosis kit of the envenomation by this snake.
\end{abstract}

KEYWORDS: Antivenom, immunogenicity, ELISA, venom snake.

\footnotetext{
${ }^{1}$ Laboratorio de Biología Molecular. Facultad de Ciencias Biológicas.

Universidad Nacional Mayor de San Marcos. Lima 01. Perú

${ }^{2}$ Instituto de Medicina Tropical "Daniel Alcides Carrión”. Facultad de Medicina Humana.

Universidad Nacional Mayor de San Marcos. Lima 01. Perú.
} 


\section{INTRODUCCIÓN}

Los venenos de serpientes son mezclas complejas de sustancias, principalmente proteínas, producidas por una glándula seromucosa, e inoculados mediante un aparato especializado compuesto por colmillos acanalados los cuales ingresan por presión en los tejidos. Las ponzoñas procedentes de serpientes de la familia Viperidae causan principalmente hemorragia, edema, mionecrosis y disturbios en la coagulación, siendo la incidencia mundial anual de mordedura por serpientes de 5 millones de habitantes [1] con cálculos de muertes estimados entre 60 a 80 mil [2]. Por ello, el ofidismo constituye un problema de salud pública para los países que cuentan con una fauna ponzoñosa muy variada, tal como ocurre en el Perú [3].

Dentro de esta familia, destacan las serpientes del género Bothrops, las cuales habitan una extensa región de América y en el Perú se presentan hasta 17 especies, siendo el "jergón", Bothrops atrox, la más abundante, peligrosa y causante del $90 \%$ de los accidentes ofídicos en el Perú [3,4]. Como consecuencia de la mordedura se presenta dolor intenso en la zona afectada, edema, hemorragia y un severo descenso de la presión arterial que ocasiona la muerte; en otros casos una masiva necrosis que lleva a la amputación del miembro afectado [5].

Estudios previos del veneno de $B$. atrox han determinado actividades esterásica, fibrinolítica y kininogenásica, las cuales se encuentran relacionadas con la marcada acción del veneno sobre la coagulación sanguínea [6]. Entre las enzimas relacionadas con esta acción se encuentran las similares a trombina (ESTs), las cuales de igual forma que la trombina, producen coágulos que bloquean la circulación sanguínea aunque su mecanismo de acción sea diferente, ya que preferentemente liberan sólo fibrinopéptidos A o $\mathrm{B}$, mientras que la trombina produce la liberación de ambos fibrinopéptidos de la molécula del fibrinógeno, es decir, los fibrinopéptidos A y B $[7,8]$. Esta enzima ha sido detectada en varios venenos botrópicos incluído $B$. atrox utilizando como sustratos plasma bovino como también fibrinógeno bovino y canino [9]. En un estudio previo, Sandoval et al. [10] estudiaron la inmunogenicidad del veneno completo de $B$. atrox destacando el grupo de proteínas de mediano peso molecular (30 kDa aproximadamente) como las más inmunogénicas. Así mismo, Sandoval et al. [11,12], lograron purificar la EST de B. atrox e identificar algunas propiedades bioquímicas y moleculares como el peso molecular y su semejanza estructural y de secuencia con otras proteínas coagulantes de venenos de serpientes.

Tomando como punto de partida estos antecedentes, en el presente trabajo se ha realizado una evaluación de la inmunogenicidad de la enzima similar a trombina del veneno de la serpiente Bothrops atrox, y posteriormente se estudió la reactividad cruzada del suero hiperinmune producido contra los venenos de serpientes peruanas de la familia Viperidae, mediante técnicas inmunoenzimáticas. Estos resultados contribuirán al mejoramiento de la calidad de los antivenenos polivalentes comerciales producidos en el Perú, así como al desarrollo de kits de diagnóstico rápidos y específicos para la detección del envenenamiento por serpientes.

\section{MATERIALES Y MÉTODOS}

\section{Material biológico}

Se empleó el veneno de la serpiente Bothrops atrox obtenido a partir de ejemplares procedentes de Pucallpa, departamento de Ucayali, y mantenidos en el Serpentario "Oswaldo Meneses", Museo de Historia Natural, UNMSM (Fig. 1). El veneno fue extraído por presión manual, después liofilizado y mantenido en congelación hasta su uso. Por otro, para evaluar la reactividad cruzada se emplearon venenos de las especies: B. brazili, $L$. muta y $C$. durissus, procedentes de ejemplares mantenidos en el mismo serpentario. Asimismo, para la obtención del suero hiperinmune se emplearon conejos albinos machos Nueva Zelanda $(2,5 \mathrm{~kg}$ de peso aprox.), los cuales fueron mantenidos en el Instituto de Medicina Tropical “Daniel Alcides Carrión” (UNMSM).

\section{Cuantificación de proteínas}

La cantidad de proteína fue calculada midiendo la absorbancia de luz UV a $280 \mathrm{~nm}$ [13] en un espectrofotómetro Shimadzu UV 120-02. Además se empleó el método de Lowry et al. [14] modificado [6] utilizando un fotocolorímetro y albúmina sérica bovina como proteína estándar.

\section{Purificación de la enzima similar a trombina}

Para la purificación de la EST del veneno de $B$. atrox se empleó la metodología estandarizada por Sandoval et al. [12]. De manera resumida, se utilizaron $200 \mathrm{mg}$ de veneno crudo disuelto en buffer acetato de amonio 0,05 M, pH 6,0; los cuales 
fue separados mediante tres pasos cromatográficos en Sephadex G-75, CM Sephadex C-50 y finalmente en Agarosa-PAB. Para el monitoreo de la purificación se empleó la actividad enzimática sobre BApNA [15] y las fracciones con mayor actividad fueron concentradas y mantenidas en congelación hasta su uso. La pureza de la enzima fue analizada mediante electroforesis en geles de poliacrilamida en condiciones denaturantes con SDS (PAGE-SDS) [16].

\section{Protocolo de inmunización}

Para la producción de anticuerpos anti-EST de B. atrox, se inmunizaron conejos albinos con 150 $\mu \mathrm{g}$ de enzima, previamente emulsificada con un volumen equivalente de adyuvante completo de Freund (CFA) e inyectados por vía intradérmica, en cada uno de los animales en volúmenes de 0.25 $\mathrm{mL}$ seleccionando cuatro lugares del dorso. Luego de 10 días se aplicaron tres dosis de refuerzo con $150 \mu \mathrm{g}$ de la enzima, preparadas en adyuvante incompleto de Freund (IFA) a intervalos de 20 días. Diez días después de aplicada cada dosis de refuerzo, se extrajo sangre a partir de la vena marginal de la oreja y al finalizar el protocolo de inmunización, la sangre se obtuvo mediante punción cardiaca, a fin de obtener los anticuerpos reactivos en el suero contra la proteína en estudio (Fig. 2).

\section{Detección de anticuerpos contra la EST del veneno de $B$. atrox y determinación de la reactividad cruzada contra otros venenos de serpiente.}

Los anticuerpos IgG anti-EST de B. atrox fueron detectados mediante la técnica de ELISA [17]. Para ello se emplearon placas de 96 pocillos cubiertas con $100 \mu \mathrm{L} /$ pocillo de EST de B. atrox (1 $\mu \mathrm{g} / \mathrm{mL}$ ), durante una noche a $4{ }^{\circ} \mathrm{C}$. Después de tres lavados sucesivos, las placas fueron bloqueadas por $1 \mathrm{~h}$ a $37{ }^{\circ} \mathrm{C}$ y posteriormente se aplicaron diluciones seriadas del suero de conejo obtenido al final del protocolo de inmunización (día 70) e incubados durante $1 \mathrm{~h}$ a $37^{\circ} \mathrm{C}$. Las placas fueron lavadas nuevamente y los anticuerpos unidos fueron detectados empleando anti-IgG de conejo conjugado con fosfatasa alcalina, seguido de la adición del sustrato respectivo. La reacción se detuvo mediante la adición de $\mathrm{NaOH} 3 \mathrm{M}$ registrándose la absorbancia a $405 \mathrm{~nm}$ en un lector de placas Titertek Multiskan PLUS MKII. El título del suero respectivo correspondió a la inversa de la dilución del mismo la cual produjo un 50\% de la máxima absorbancia registrada.

Por otro lado, se evaluó la reactividad cruzada del suero anti-EST de B. atrox contra los venenos de B. atrox, B. brazili, L. muta y C. durissus, siguiendo para esto los mismos parámetros utilizados en la detección de anticuerpos, y expresada como porcentaje de las densidades ópticas resultantes de la reacción entre los mencionados venenos y el suero anti-B. atrox considerando como $100 \%$ el valor de absorbancia obtenido entre la EST de B. atrox y su respectivo suero a una dilución equivalente al título obtenido para esta proteína.

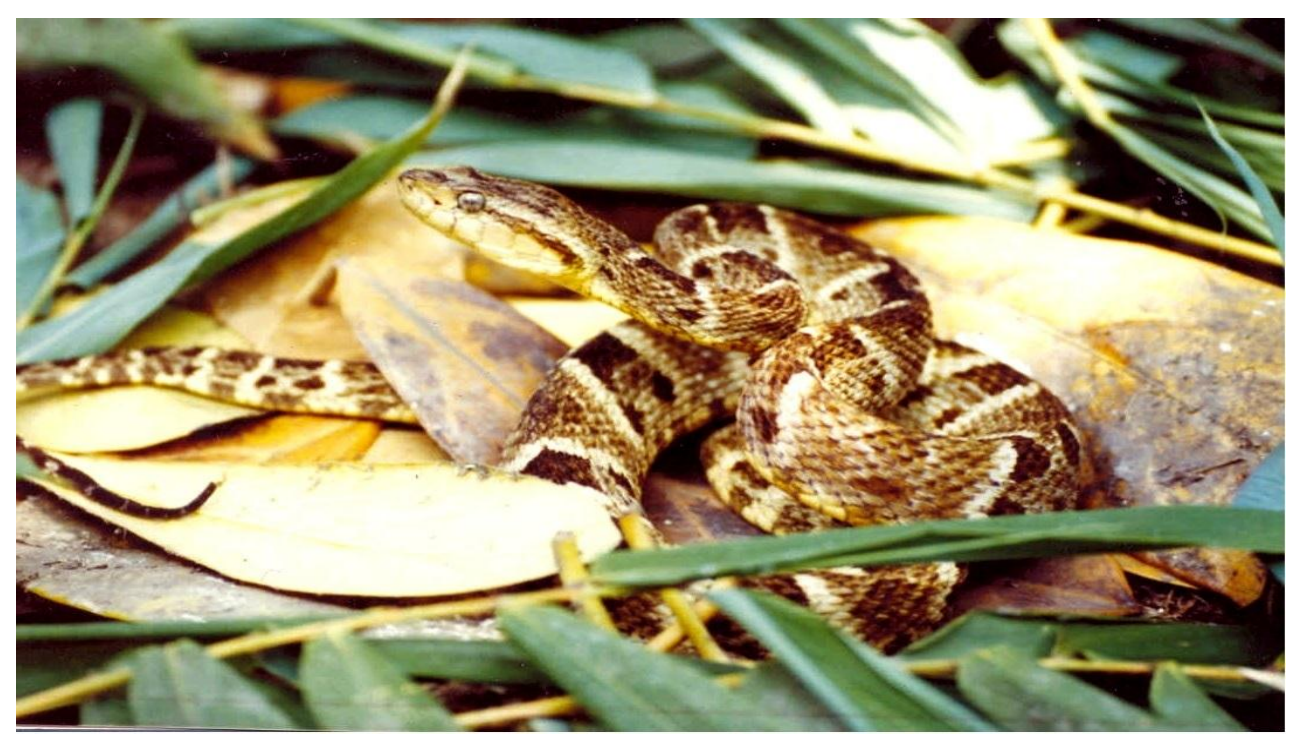

Fig. 1. La serpiente peruana Bothrops atrox ("jergón"). 


\section{RESULTADOS}

\section{Detección y título de anticuerpos contra la EST del veneno de Bothrops atrox}

La (Fig. 2) muestra los niveles de producción de anticuerpos IgG específicos contra la EST del veneno de B. atrox, la cual alcanzó su máximo valor después de la tercera dosis de refuerzo (día 50), y se mantuvo hasta el final del protocolo de inmunización. Asimismo, se determinó el título de anticuerpos anti-EST de B. atrox en el suero obtenido al final del protocolo de inmunización, el cual correspondió al valor de 64000 .

\section{Reactividad cruzada determinada por ELISA}

Se obtuvo un valor máximo de densidad óptica a $405 \mathrm{~nm}$ producto de la reacción entre los anticuerpos anti-EST y la EST de B. atrox (Fig. 3). Además, se observó que el suero reaccionó de forma cruzada con los otros venenos de serpiente, pero con menor intensidad, siendo los valores de reactividad cruzada para los venenos de $B$. atrox, B. brazili, L. muta у C. durissus, de $9.9 \%, 9.6 \%$, $5.1 \%$ y $4.8 \%$, respectivamente.

\section{DISCUSIÓN}

Los venenos de serpientes son mezclas altamente complejas de componentes principalmente proteicos y por esta razón, tanto estas ponzoñas como sus enzimas $\mathrm{y}$ toxinas purificadas, han sido utilizadas para la inmunización de diferentes tipos de animales de experimentación a fin de evaluar su potencial inmunogenicidad y para la elaboración de los antídotos respectivos. En el presente estudio se utilizaron conejos albinos de raza Nueva Zelanda como animales de experimentación los cuales fueron inmunizados por vía subcutánea empleando cuatro dosis de la EST del veneno de Bothrops atrox durante un periodo de 70 días, los cuales fueron emulsificados con adyuvante completo de Freund (CFA) para la inmunización primaria y adyuvante incompleto de Freund (IFA) para las dosis de refuerzo. La eficacia de este método fue monitoreada mediante la técnica de ELISA (Fig. 2) donde el aumento de la absorbancia a $405 \mathrm{~nm}$ indica la formación de inmunocomplejos producto del reconocimiento antígeno-anticuerpo.
Como se puede apreciar, los anticuerpos pudieron ser detectados a partir del día 20 y su producción fue sostenida alcanzándose los niveles máximos a partir del día 60 hasta el final del protocolo. Asimismo, mediante esta técnica se pudieron detectar anticuerpos específicos con un título de 64000, lo cual manifiesta que la proteína en estudio es inmunogénica. En este aspecto, el procedimiento empleado resulta práctico, eficiente y de corta duración, convirtiéndolo en un método útil para la obtención de anticuerpos contra la EST del veneno de Bothrops atrox.

Por otro lado, se estudió la reactividad inmunológica cruzada entre la EST de Bothrops atrox y otros venenos de serpientes peruanas consideradas de importancia en salud pública por la incidencia de su mordedura [5]. Como resultado de este análisis se obtuvo la densidad óptica más alta entre la EST del veneno de B. atrox y su respectivo suero (Fig. 3). Posteriormente, mediante ensayos de titulación, se observó reactividad cruzada con los otros venenos de serpiente, donde se obtuvieron títulos bajos contra los venenos de $B$. atrox y B. brazili, seguido por los venenos de Lachesis muta y Crotalus durissus (Fig. 3).

Los anticuerpos producidos contra la EST del veneno de Bothrops atrox mostraron un bajo nivel de reactividad cruzada contra los venenos en estudio, por lo que los estudios de inmunogenicidad de esta proteína serían la base para la preparación de anticuerpos específicos de especie como paso preliminar en el desarrollo de kits de diagnóstico. Un avance dentro de estos estudios lo reporta el trabajo de Sandoval et al. [18], donde utilizando columnas de afinidad con el veneno inmovilizado de $B$. atrox se pudieron capturar los anticuerpos IgG específicos a partir del suero hiperinmune. Asimismo, la técnica de ELISA puede ser utilizada para la determinación de la concentración de la EST tanto en ensayos in vivo como in vitro, $\mathrm{y}$ así evaluar la inmunoreactividad de estos componentes en las personas administradas, a fin de aumentar el tiempo de circulación de estos en los fluidos biológicos. 


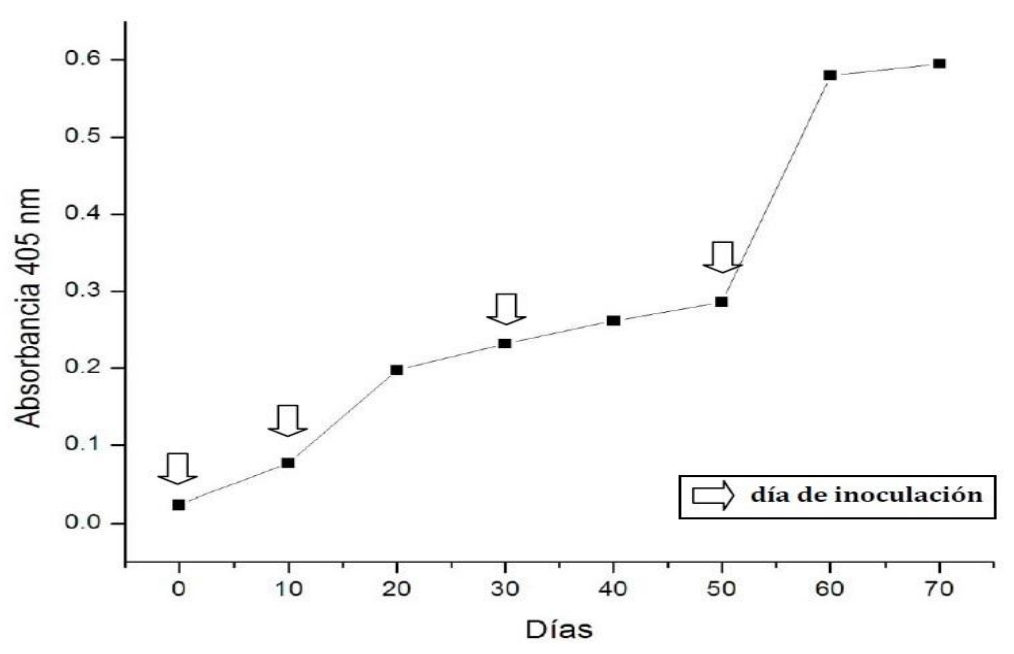

Fig. 2. Detección de IgG anti-EST de B. atrox en el suero de conejos inmunizados mediante la técnica de ELISA. Las placas de 96 pocillos fueron cubiertas con $100 \mu \mathrm{L}$ de EST de $B$. atrox $(1.0 \mu \mathrm{g} / \mathrm{mL})$ y se dejaron incubar durante una noche a $4{ }^{\circ} \mathrm{C}$. Luego las placas fueron incubadas con suero de conejo obtenido al día 90 del protocolo de inmunización (1/25600) y los inmunocomplejos fueron detectados con un anti-IgG de conejo (1/4000) acoplado a fosfatasa alcalina usando como sustrato p-nitroanilida $(1 \mathrm{mg} / \mathrm{mL})$. La reacción enzimática fue detenida al cabo de 30 min con $\mathrm{NaOH} 3 \mathrm{M}$, registrándose la absorbancia a $405 \mathrm{~nm}$ en un lector de placas.

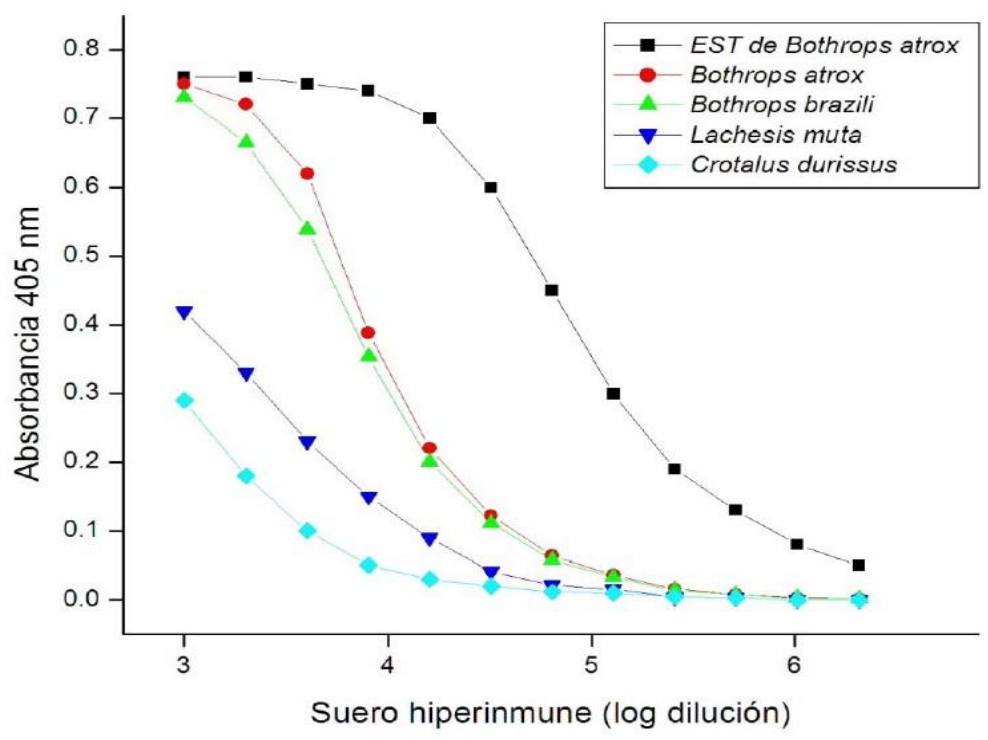

Fig. 3. Evaluación de la reacción inmunológica cruzada del suero anti-EST con la EST de $B$. atrox y algunos venenos de serpientes peruanas mediante la técnica de ELISA. Se cubrieron placas de 96 pocillos con EST $(1.0 \mu \mathrm{g} / \mathrm{mL}, 100 \mu \mathrm{L} /$ pocillo) y los venenos de Bothrops atrox, Bothrops brazili, Lachesis muta y Crotalus durissus $(0.25 \mu \mathrm{g} / \mathrm{mL}, 100 \mu \mathrm{L} /$ pocillo) para luego ser incubados con suero hiperinmune anti-EST (diluido a partir de 1/1000). Los inmuncomplejos fueron visualizados mediante incubación con anti-IgG de conejo acoplado a fosfatasa alcalina (1/4000) seguido de la adición de p-nitroanilida. 


\section{CONCLUSIONES}

La enzima similar a trombina del veneno de Bothrops atrox presenta una elevada inmunogenicidad, así como una baja reactividad cruzada con otros venenos de serpientes peruanas. Esto la convertiría en una potencial candidata para la elaboración de un kit de diagnóstico rápido y específico del envenenamiento ofídico por esta serpiente.

\section{AGRADECIMIENTOS}

La realización del presente trabajo ha sido posible gracias a los fondos provenientes del Programa Nacional de Innovación para la Competitividad y Productividad - Innóvate Perú (Contrato No 131-FINCyT-IB-2013).

\section{AUTOR DE CORRESPONDENCIA:}

Gustavo A. Sandoval, Facultad de Ciencias Biológicas, Universidad Nacional Mayor de San Marcos.

Av. Venezuela s/n - Ciudad Universitaria, Lima Perú.

Teléfono: +51-1-6197000 Anexo 1558.

E-mail: gsandovalp@unmsm.edu.pe

\section{REFERENCIAS BIBLIOGRÁFICAS}

1. Chippaux JP, Goyffon M. Venoms, antivenoms and immunotherapy. Toxicon. 1998;36(6):82346.

2. Warrell DA. Clinical features of envenoming. In: Envenoming and their treatments. cd. Bon, C.; Goyffon, M. pp. 63-76. Fond. Marcel Mérieux, Lyon. 1996.

3. Yarlequé A. Las serpientes peruanas y sus venenos. Fondo Editorial, Universidad

4. Nacional Mayor de San Marcos. Lima-Perú. 2000, 78 pp.

5. Loja D, Aviles R, Necochea Y, Vilca M, Castro J. Ofidismo por Bothrops atrox: estudio clínicoepidemiológico. Diagnóstico. 2000; 39(5):2615.

6. Lévano J, Fernández R. Diagnóstico y tratamiento de los accidentes por animales ponzoñosos. Instituto Nacional de Salud, Ministerio de Salud, Lima, Perú. 1era edición. 2004, 74 pp.

7. Loayza S, Morante Y, Campos S, Yarlequé A. Enzimas proteolíticas en el veneno de las serpientes peruanas Lachesis muta y Bothrops atrox. Bol Soc Quim Perú. 1985; 52(3):151-63.
8. Braud SC, Bon C, Wisner A. Snake venom proteins acting on hemostasis. Biochimie. 2000; 82(9-10):851-9.

9. Lu Q, Clemetson JM, Clemetson KJ. Snake venoms and hemostasis. J Thromb Haemost. 2005; 3(8):1791-9.

10. Orejuela P, Zavaleta A, Salas M, Marsh N. Thrombin-like activity in snake venoms from Peruvian Bothrops and Lachesis genera. Toxicon. 1991;29(2):1151-4.Sandoval GA, Mendoza J, Roldán W, Espinoza Y, Solis H, Yarlequé A. Immunogenicity of Bothrops atrox (Ophidia: Viperidae) venom and its evaluation by immunoenzymatic methods. Rev Peru Biol. 2011;18(3):335-41.Sandoval GA, Ruiz N, Lazo F, Rodriguez E, Yarlequé A, Zingali RB. Isolation and partial characterization of a thrombin-like enzyme from Bothrops atrox Peruvian snake venom “Jergon”. Rev Soc Quim Perú. 2010a;76(2):156-64.

11. Sandoval GA, Lazo F, Rodriguez E, Yarlequé A, Zingali RB. Molecular identification and activity upon chromogenic substrates of avenombin A from Bothrops atrox Peruvian snake venom. Rev Peru Biol. 2010b;17(3):36570.

12. Warburg O, Christian W. Isolierung and Kristallisation der Garungs ferments enolase. Biochem Z. 1941;310:384-421.

13.Lowry OH, Rosebrough NJ, Farr AL, Randall RJ. Protein measurement with the Folin phenol reagent. J Biol Chem. 1951;193(1):265-75.

14.Erlanger BF, Kokowsky N, Cohen W. The preparation and properties of two new chromogenic substrates of trypsin. Arch Biochem Biophys. 1961;95:271-8.

15.Laemmli UK. Cleavage of structural proteins during the assembly of the head of bacteriophage $\quad \mathrm{T} 4 . \quad$ Nature. 1970;227(5259):680-5.

16.Engvall E, Perlman P. Enzyme-linked immunosorbent assay (ELISA). Quantitative assay of immunoglobulin G. Immunochemistry. 1971;8(9):871-4.

17. Sandoval G, Lerma L, Rodríguez E, Yarlequé A, Espinoza Y, Solis $\mathrm{H}$, et al. Purification of polyclonal antibodies against Bothrops atrox Peruvian snake venom ("Jergon") by affinity chromatography. Rev Soc Quim Perú. 2006;72(3):140-9

Recibido: 20/01/2015

Aceptado: 10/02/2015 